\title{
Karakoram and NW Himalayan shear zones: Deciphering their micro- and macrotectonics using mineral fish
}

\author{
Soumyajit Mukherjee* and Arvind K J ain \\ Department of Earth Sciences, Indian Institute of Technology Roorkee, Roorkee 247667, Uttaranchal, INDIA \\ * To whom correspondence should be addressed. E-mail: msoumyajit@yahoo.com
}

Sheared metamorphic belts of Karakoram and northwest Himalaya such as the Karakoram Metamorphic Belt (KMB), the Tso Morari Crystallines (TMC) and theHimalayan Metamorphic Belt (HMB) reveal top-to-southwest overthrust sense of ductile shearingasthefirstorder structures, which areproduced during themain Himalayan $D_{2}$ deformation event (Jain etal. 2002). These belts reveal mica fishes and similar fish-shaped singlegrainsand aggregates of amphibole, feldspar, staurolite, recrystallized quartz, calcite, epidote, sillimanite, apatite and garnet, and thereforea non-genetic term 'mineral fish' can beused to describe such generallyasymmetric sheared objects. Mineral fish has been classified morphologicallyinto singleand compositetypes, both of which have been subdivided into 13 varieties (In this classification, three basic shapes of the mineral fish are considered: sigmoid, parallelogram and lenticular. These basic fish shapes can further be modified by fish mouth(s) and secondary shearing. The overall shape asymmetry of mineral fishes and its angular relationship to the C-plane is the most reliable primary shear sense indicator. On the other hand, orientation of its cleavage traces with respect to the C-plane, if any, is not always indicative of true sense of shearing. Stair stepping of fish tail(s) and deflected tip(s) of any fish variety, and the snake fish itself, are indicative of secondary shear sense. Mineral fish of any mineral species become the most abundant shear structures in combination with the $\mathrm{C}$-planes, and keeping theaboverestrictionsin mind, thesebecomethemostimportant structuresin deciphering the sense of ductileshearing. Different mineralsmay acquire, and multiply into, thesamefish shapeby entirely different mechanisms. For single mineral fishes, such mechanisms are simple shear, pulling of the grain corners involving sequential change from sigmoidal- to elongated sigmoidal fish with decreasing aspect ratio $\mathrm{R}$ and inclination $\alpha$, fracturing in any direction, boudinaging at the gaining corners, and pressure solution concomitant to shearing at the loosing corners of theevolvingmineral fish. Material lost from theloosing corners of the single mineral fish by pressure solution might migrate and deposit at its gaining corners. Thus, while a pair of corners undergoes smoothening, the other observes extension and recrystallization of mineral.

Study of mineral fishes from the $X Z$ thin-sections of the Karakoram- and northwest Himalayan shear zone rocks reveal consistenttop-to-SW sense of ductileshearing within theHigher
Himalayan Crystallines (HHC), and also shear sense reversal (SSR), which is characterized by relic and rare mineral fishesfrom theHimalayan shear zones of different tectonic belts: theZanskar Shear Zone (ZSZ), and from theTso-Morari Crystallines (TMC). There, the SSR is defined as $180^{\circ}$ switch in the sense of shearing and doesnot includerareantithetic shearing, which isassociated and at high angle to the primary shear plane. In the ZSZ and the TMC, theSSR has been observed on micro-scalein thefollowing ways: (i) Type-4 mineral fish (one mineral fish cutting the other and pointing $180^{\circ}$ differencein the sense of shear from the other); and (ii) two single mineral fishes, with same or different subvarieties, pointing opposite shear sense. Such pairs of mineral fishes are either bounded by the same pair of C-planes, or of different pairs, which are sub-parallel to each other. In both the ZSZ and the TMC, the earlier C-planes were reactivated as the shear planes for the retro shear. However, the difference in SSR in these two tectonic scenarios is that while in the ZSZ, top-toSW sense is the relic shear sense, and top-to-NE as the most dominant one, in the TMC opposite is the case. Observed SSR in the ZSZ and uniform shear sense in the HHC is in accordance with the proposed 'combined ductile shear and channel flow model' for theH Higher Himalayan Shear Zone(HHSZ) exhumation by Mukherjee and Jain (2003). On the other hand, rarebut clearcut occurrence of mineral fishes giving top-to-NE shear sense from the TMC is a new observation, and interestingly, such SSR has not yet been reported from the field (e.g., Jain et al., 2003). Relic top-to-NE sense of shear within the TMC might be due to the shear induced crustal burial at about $90 \mathrm{~km}$, which resulted in itsultra-high pressuremetamorphism.

\section{References}

Jain AK, S Singh and RM Manickavasagam. 2002. Himalayan Collisional Tectonics. Gondwana Res Group Mem 7, Field Science Publishers. Hashimoto. 119p

Jain AK, S Singh, RM Manickavasagam, M Joshi and PK Verma. 2003. HIM PROBE Programme: Integrated Studies on Geology, Petrology, Geochronology and Geophysics of the Trans-Himalaya and Karakoram. Mem Geol Soc India 53: 1-56

Mukherjee S and AK Jain. 2003. Exhumation Patterns within the Higher Himalayan Shear Zone (HHSZ)- a Combined Ductile shear and Channel Flow Model. Abst Vol 2-4 April. 18 $8^{\text {th }}$ Himalaya-KarakoramTibet Workshop. MonteVerita, Ascona, Switzerland. 83-86 